\title{
Managing healthcare reform in Hungary: challenges and opportunities
}

\author{
Miklós K Szócska, János M Réthelyi, Charles Normand
}

The reform of healthcare services is a priority in transitional Hungary, but managing these changes is fraught with difficulties due to the political climate and managerial inexperience

The past 15 years in Hungary have been characterised by unique changes. Apart from democratisation and managing the immediate crises caused by the collapse of the economy in the early 1990s, a strong part of the reforms was a desire to build Western models of health care and the necessary social and economic infrastructure. Hungary was forced to start substantial reengineering of health services that requires a recognition of the interdependency between policy making and implementation and the management of change.

Policy making and managing organisations are generally viewed as fundamentally different. Even a quick review of the reforms ongoing in Hungarian health care, however, challenges this perspective. Policy and management are highly interrelated and the management of change is critical to successful implementation of policy. We examined some of the factors that facilitate or limit change and recommend action for improving the management of these processes.

\section{Policy development}

To understand the interrelatedness of implementing policy and managing change, first we looked at patterns of policy development that shape the environment of change in healthcare organisations. The process of reform is part of a policy cycle (fig 1). Three key factors influenced the cycle in Hungary, and all are strongly linked to managerial constraints that affect change:

- In the emerging democracy, the new administration consisted of promising but administratively inexperienced reformers.

- With the exception of one full mandate, health ministers were constantly changing (nine in office since $\left.1990^{2}\right)$. But the magnitude of their planned re-engineering of the healthcare system needed 4-6 years of steady effort for effective implementation. The number of major reform programmes initiated by the various administrations is also striking. Each change in minister led to change in reform objectives. Frequent changes in administration also brought change in management in many state owned or municipal hospitals.

- The bureaucratic approach to health reform is culturally determined yet universal. ${ }^{3}$ The reforms were mainly through new regulations, structural interventions, and normally the only instrument of change was

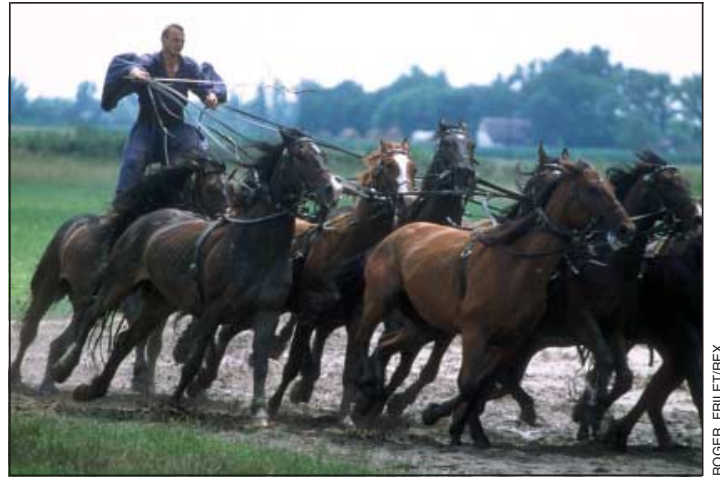

Now turn right

legal compliance supported by loosely coupled training assistance. Using law and regulation to effect change is seen as coercive. This is a problem in an era when government is being democratised and can lead to political crisis.

These characteristics created an extraordinary perverted policy cycle in Hungary. A new administration (government or minister of health) assumes office after scheduled elections or a crisis in government. It has to respond to expectations to tackle serious problems involving the provision of health services, but it also has to prove that it is better than the previous one.

The new administration brings new ideas, mostly based on party ideology or personal ideas of the minister, interest groups, or stakeholders with affiliation to the party. The new minister brings in new people with new ideas not just in political positions but also in administrative positions, even at healthcare institutions. They are rarely well prepared in terms of planning and administrative capacities. Knowing that their window of opportunity is narrow, ministers have to intervene at the start of their mandate. To tackle serious problems they instigate far reaching interventions that are codified in new regulations. But the process for approving the new rules rarely involves the people who are actually responsible for translating the regulations into developments, and communication is generally one way.

Because of rapid interventions and inadequate communication, policy makers and organisational managers have different perceptions of the ongoing process and its impact. Although senior Hungarian
Health Services Management Training Centre, Semmelweis University, 1125 Budapest, Kútvölgyi út 2, Hungary

Miklós K Szócska acting director János M Réthelyi visiting research fellow

Faculty of Health Sciences, University of Dublin Trinity College, Dublin, Ireland

Charles Normand Edward Kenned professor of health economics

Correspondence to: M K Szócska szocska@emk.sote.hu

BMJ 2005;331:231-3

Parallel key factors influencing the policy development cycle and organisational change

\begin{tabular}{ll}
\hline Inexperience of reformers & Inexperience of new generation of managers \\
\hline Frequent change in administration and reform objectives & Exposed to change in the policy environment; frequent change in management or change objectives \\
\hline Dominance of bureaucratic approach to reform & Inherited dominance of authoritarian management \\
\hline
\end{tabular}




\section{Box 1: Important managerial constraints}

- The manager has no exact vision of the end state of organisational changes

- The manager does not consider the risks during change and forgets to set up contingencies and alternative actions

- The manager is bounded by their personal interests and leaves the previous system's authoritarian and hierarchical relationships unchanged

- The manager does not establish relevant administrative capacities (personnel, infrastructure, etc) to implement changes

- The manager sets unrealistic goals and objectives, so the half finished project has to be stopped

- Without analysis, the manager forces changes that ignore present realities, the decisions are made ad hoc

- No plans and procedures are prepared for the change so the project is not implemented systematically

- The manager has no training and attitude relevant to the needs of the change, and they do not have learning strategies

- The managerial board or top management has no agreed strategy

- The manager does not take organisational resistance into consideration.

Thus they repeatedly lose initiatives on resistance from employees or other stakeholders

- Obstacles emerging in the project cause the manager to suddenly give up the organisational vision

- No strategies exist in the organisation for ensuring that tasks are done; tasks are done in a casual way

- The manager does not clarify and does not make the change objectives understandable for employees; communication is disturbed and noisy

- The manager has no personal credibility, or has not built up their personal credibility; their words carry no weight for the employees

- The manager does not take steps to clarify changing roles and responsibilities

- The manager does not establish formal channels of communication in the organisation that could support the change project

health policy makers believe that changes in health care were frequent and fundamental between 1990 and 1998, top and middle managers in healthcare organisations think that although reforms were frequent they were not fundamental and were often superficial. ${ }^{4}$ The gap in perception between policy makers and organisational managers shows the location of a special interface (a synaptic location) between policy makers and organisational managers. The ignorance of the nature of exchange at this interface (synaptic junction) is one of the most important causes of failed attempts to reform. Together with elections, exceptional elections, political crises, scandals, dissatisfaction with performance of government,

\section{Box 2: Causes of organisational resistance}

- Lack of information related to the actual change project

- The people expected to implement the changes are not involved in the decisions and the preparation of decisions

- Hectic, contradictory, and disturbed top-down communication leads to repeated misunderstandings; management loses its credibility among employees

- Interest in the organisation is mainly dominated by private and group interests that are antagonistic to those of the organisation and the employees

- Financial incentives supporting the changes are lacking

- General uncertainty about the future state; who will do what and how? it can force the regular or the premature change in the administration or the minister. These changes are mainly politically driven and do not help the development of sustainable health reforms. Indeed they increase confusion and fuel the perverted policy cycle.

Most of the time ministers have to leave office while parts of their reform have been implemented and before there is evidence of their effect or usefulness. Vacuums and disturbances are left behind. People in the system know that implementation of reform programmes initiated by the previous ministers or governments was often halted by their successors. As they do not want to waste energy and resources they immediately suspend implementation, even if continuing with it made more sense. They know that changing a minister also means changes in administrative positions. Discontinuity in management also generates a power vacuum. The interrupted and fragmented health policy development in turn generates professional confusion. People lose faith in particular reforms, although the real problem is not what the administration wanted to do as a technical solution, but how they wanted to introduce it. The new administrations then have to struggle with the complex set of distrust, decreasing the chances to find feasible solutions, and the cycle continues. Again, a new minister steps in, with new ideas and an even stronger sense of urgency to intervene. As the cycle continues, the tension gradually increase and the phases of the cycle become more characteristic.

\section{Organisational change}

Throughout the policy cycle, health reform involves organisations. Most of the reforms can be realised only through the organised action of organisations exposed to the new legislations. These often require the restructuring of organisations or the entire ownership. In the late 1980s and early 1990s, most top and many middle managers in healthcare organisations in Hungary were replaced by new enthusiastic but often inexperienced and untrained managers. So the complex task of coping with policy change and reforming organisations was in the hands of a new managerial generation. The three factors that influenced the development of the perverted policy cycle show parallels at the organisational level (table, previous page).

The unprecedented reforms resulted in many projects to change healthcare organisations. As a consequence of the inexperience of managers, frequent change in management, and inadequate management practice, many projects failed. A high failure rate in change is a universal challenge for managers and policy makers. A recent study reports a $70 \%$ failure rate in organisational change projects. ${ }^{5}$ In a vulnerable society in transition, such as Hungary, however, sustainable change has high stakes. This motivated us to understand the cause of failures. We analysed large numbers of change projects ${ }^{6}$ that were planned and implemented in Hungarian healthcare organisations and came to the conclusion that failures can be attributed to managerial failures of change managers and organisational resistance that change managers generated through their actions. The most important failures and causes for resistance are listed in box 1 and box 2 . 


\section{Feasible change and reform}

Our findings outline a set of criteria that are critical to the feasibility and sustainability of change efforts (box 3). Given that health reforms generate a need for adaptational change efforts in organisations so the criteria should also be taken into account when determining the feasibility of the reforms.

Just as organisational managers have to consider whether they have appropriate administrative capacities to achieve their objectives, policy makers should judge organisational managerial capacities to assess overall feasibility. Failure to assess this capacity undermines the most worthwhile reform efforts and limits the ability of the countries of Hungary and similar central and eastern European countries to meet the challenges and opportunity that are presently available.

Leaders of the change project know where they are going-Refers to the level of setting the vision of the future state, the goals and objectives is the area in which most failure occurred. It is important to know the goals or to outline the roadmap of change. According to our findings, lack of information on the future state of change is the most important cause of organisational resistance. Status quo defending routines only kick in when there is a lack of information on the future (end) state of the change. If people involved in the change can receive relevant information they are willing to consider cooperation.

Incentives are well tailored towards the desired future state or a critical mass of people is involved, willing, and capable of working towards change-The incentive system in Hungarian health care represents the most complex trap in change and reform efforts. Tuning the incentive system is the most complex policy challenge even when the incentives are obvious and follow official channels. With the heritage of gratitude and informal payments it requires large scale efforts to find a way forward even at an organisational level. However, leaving the incentive system untouched meant a direct failure of change and restoration. Box 3: Critical factors in planning and
managing feasible change and reform

- Leaders of the change project know where they are going

- Communication; shared vision

- Appropriate change infrastructure is available for implementation, or necessary developments are outlined if they are missing

- Incentives are well tailored towards the desired future state and/or a critical mass of people is involved, willing and capable to work towards change

- There is consistency in implementation

- The change manager has personal change management competencies, experience of implementing change and credibility among the employees, and this is maintained throughout the change process

- Resistance to change is managed by involvement and communication

\section{Summary points}

In itself the dynamics (severity and frequency) of health reform have critical impact on the sustainability of reform efforts

The realities of organisational change are as important for a policy maker as the testing of the environment of organisations for an organisational strategist

To be a reformer or a leader of change requires preparation for the challenges

The lack of change related information is the most intensive trigger for organisational resistance

The sharper contrasts of reform experiences in Hungary help our understanding of reform failures in less dramatically changing health services as well

Resistance to change is managed by involvement and communication-Overcoming resistance is difficult so the best strategy is prevention. Setting clear engaging goals, sharing them through communication, establishing involvement and ownership, and introducing the future state in transparent terms seem to be the best strategies for managing resistance even in crisis situations. Management of resistance in authoritarian systems however means breaking resistance. According to our experience it only contributes to the escalation of the conflict.

Failing change projects and the frustration of the perverted policy cycle are familiar phenomena to many of us working in health services even outside the boundaries of Hungary and central Europe. Using the contrasted case study of Hungary might provoke rethinking of reform and organisational change efforts in a European context.

We thank Katalin Husser, Péter Gaál, and Arnold Kaluzny. Contributors and sources: All authors were involved in managing change in healthcare in Hungary and shared their experiences. MKS is guarantor.

Funding: Health Services Management Training Centre.

Competing interests: None declared.

Ethical approval: Not needed.

1 Healy J, McKee M. Reforming hospital systems in turbulent times. Eurohealth Special Issue 2001 Autumn;7(3):2.

2 Szócska MK. Survey among central and eastern European and post-Soviet republics' health managers on the changes in government administrators in their health care sectors, 1999-2004. Budapest: Semmelweis University Health Services Management Training Centre, 2004

3 Lavis JN, Posada FB, Haines A, Osei E. Use of research to inform public policymaking. Lancet 2004;364:1615-21.

4 Szócska M. Survey among senior Hungarian policy makers and hospital managers on their perception of the frequency and severity of changes in the health care, 1998. Budapest: Semmelweis University Health Services Management Training Centre, 1999.

5 Beer M, Nohria N. Cracking the code of change. Harv Bus Rev 2000;47: 127-31.

6 Szócska M. Survey on the most frequent and most important managerial failures during organisational change and causes of organisational resistfailures during organisational change and causes of organisational resist-
ance towards change, 2000-2004. Budapest: Semmelweis University Health Services Management Training Centre, 2004. 